\title{
Geopoetics in Practice
}

Edited by Eric Magrane, Linda Russo, Sara De Leeuw, and Craig Santos Perez

Milton Park: Routledge. 2020. 379 pp. £29.99 paperback. ISBN: 9780367145385

'How might creative process and product (specifically, poetry and poetics) contribute to geographical thought?' (p. 131), writes Maleea Acker in her contribution to this inspiring volume of poetry, prose, experiences, and reflections. Through diverse voices this edited collection presents geopoetics as something to do and to be worked at - it is an action. This route-finding practice aims to acquire perspective, gain empathy and to try and make something that reimagines our relationships with Earth.

The book is organised in three sections: Documenting, Reading, and Intervening. Documenting, details geopoetic projects and practice from gallery instillations to site-based performances. The authors of these chapters describe, archive, or document their practices, for example, 'Intime is performed on foreshores impacted by such air and ocean events. Each performance lasts the length of the participants' available time an energy, averaging an hour' (p.91), writes Angela Rawlings. The details and methods presented within these chapters enables the reader to engage deeply with the works, and to potentially consider how they interrogate and present their own practice.

Reading, foregrounds geopoetics as a reading practice. Many of the authors of these chapters often present others' writings and bring in literary criticism or critical-creative analysis of texts other than the author's own. 'Thus, the left-hand text is mine; the right-hand text features other voices. The right-hand quotes have been selected as a kind curatorial exercise - a bringing in of authors from both within and outside of geopoetics' (p. 131), writes Maleea Acker in the opening of her chapter Lyric Geography. Acker's chapter demonstrates how poetry and prose can be woven together in a way that encourages others both within and outside academia to engage with the entangled dialogue she presents.

Intervening, shares practices and projects that intervene in environments, places, or texts. 'How I conceptualize different poetic elements is also influenced by geography. I imagine the blank page as an excerpt of the ocean. The ocean is not 'aqua nullius'. The page then is never truly blank’ (p. 326), writes Craig Santos Perez of his Indigenous Pacific Islander Geopoetics. Santos Perez uses words and visuals to capture the interwoven poetics of Marianna archipelago, and the tilde $(\sim)$ to move between the different historical, political, and personal discourses in his work. The words and forms presented within these chapters both visualize and inspire action.

The twining of learning and practice are apparent from the opening of the book. As such this book will be of interest to anyone who is interested in learning, finding, and doing geopoetics. The authors give room and appetite for geopoetics to open-up, meaning too that you do not need to identify as a geographer to appreciate, engage, or learn from the ideas presented within the texts. 'I am most excited by the pedagogical possibilities of teaching this anthology in a Creative Writing course' (p. 12), writes editor Craig Santos Perez about the depth of possibilities for teachers and students alike to plunge into geopoetics through assignments and practices. 
In sum, Geopoetics in Practice supports and inspires exactly what the title suggests, an inspirational thrust to collaborate and create entangled poetics about the world.

Stephanie R Januchowski-Hartley

Department of Biosciences, Swansea University, UK 